\title{
Descending Spinal Cord Tract
}

National Cancer Institute

\section{Source}

National Cancer Institute. Descending Spinal Cord Tract. NCI Thesaurus. Code C12969.

Neural fibers of the spinal cord, that are grouped into tracts or fasciculi, and send motor signals from the brain to lower motor neurons. These tracts function to control muscle tone, posture, precise motor movements, spinal reflexes, and spinal autonomic functions. 